\title{
Coronary arteriography for quantitative analysis: Experimental and clinical comparison of cinefilm and video recordings
}

\author{
Although use of videotape for the recording of coronary angiograms continues to grow, the \\ validity of quantitative coronary angiographic analysis of video images remains unknown. To \\ estimate the reliability of angiographic images recorded on videotape, experimental and clinical \\ angiograms were recorded simultaneously on both $35 \mathrm{~mm}$ cinefilm and super-VHS videotape with \\ normal images and with spatial filtering of the images (edge enhancement) on a digital cardiac \\ imaging system. The experimental angiographic studies were performed with plexiglass blocks \\ and stenosis phantom of 0.5 to $3.0 \mathrm{~mm}$ in diameter. The clinical angiograms were recorded in 20 \\ patients undergoing percutaneous transluminal coronary angioplasty ( 31 frames before and 20 \\ frames after percutaneous transluminal coronary angioplasty). The cinefilm and corresponding \\ videotapes were analyzed off-line with the new version of the coronary angiography analysis \\ system. For the experimental study, measurements of minimal luminal diameter obtained from \\ cinefilm, normal-image videotape, and edge-enhanced videotape were compared with the true \\ phantom diameter. In the clinical study the agreement between measurements obtained from \\ cinefilm and measurements from normal-image videotape and edge-enhanced videotape was \\ examined. In the phantom series the accuracy and precision of quantitative coronary \\ angiography measurement for cinefilm were $-0.10 \pm 0.08 \mathrm{~mm}$, for normal-image videotape \\ $-0.11 \pm 0.18 \mathrm{~mm}$, and for edge-enhanced videotape $-0.10 \pm 0.11 \mathrm{~mm}$ (mean $\pm \mathrm{SD}$ ). In the \\ clinical series, the differences between measurements from cinefilm and normal-image videotape \\ were $0.14 \pm 0.20 \mathrm{~mm}$ and from cinefilm and edge-enhanced videotape $0.04 \pm 0.13 \mathrm{~mm}$. In the \\ experimental phantom study, the use of cinefilm resulted in the most precise measurements. in \\ the clinical study, edge-enhanced videotape provided the highest agreement with measurements \\ obtained from cinefilm. These findings suggest that cinefilm is more reliable than video as a \\ recording medium for quantitative coronary analysis in scientific studies; however, for routine \\ practice, videotape with edge-enhanced images may provide an acceptable alternative. (AM \\ HEART J 1995;129:471-5.) \\ Yukio Ozaki, MD, PhD, David Keane, MB, MRCPI, Jean Paul Herrman, MD, \\ David Foley, MB, MRCPI, Jürgen Haase, MD, PhD, Ad den Boer, BSc, \\ Carlo di Mario, MD, $\mathrm{PhD}$, and Patrick W. Serruys, MD, $\mathrm{PhD}$ \\ Rotterdam, The Netherlands
}

Coronary angiography continues to be the gold standard for coronary artery imaging in clinical practice. With the increasing demand for quantitative coro-

From Catheterization Laboratory, Intracoronary Imaging Laboratory, Department of Interventional Cardiology, Thoraxcenter, Erasmus University. Dr. Ozaki is a recipient of a grant from Takeda Medical Research (Taisha Ijo) Foundation, Japan. Dr. Keane is a recipient of a travel grant from the Peel Medical Research Trust, United Kingdom.

Received for publication April 13, 1994; accepted June 1, 1994.

Reprint requests: Patrick W. Serruys, MD, PhD, Department of Interventional Cardiology, Thoraxcenter, Erasmus University, PO Box 1738, 3000 DR Rotterdam, The Netherlands.

Copyright $\odot 1995$ by Mosby-Year Book, Inc.

$0002-8703 / 95 / \$ 3.00+0 \quad \mathbf{4} / \mathbf{1} / 60767$ nary angiography (QCA) and the development of digital acquisition systems, there has been a substantial growth in the deployment of videotape as a recording medium because of its easy handling, instant replay capability, and low cost..$^{1-4}$ In some institutions videotape has replaced $35 \mathrm{~mm}$ cinefilm as the original imaging medium. However, despite proposals for the replacement of cinefilm by videotape, the suitability of video recordings for QCA analysis has not been established. To evaluate the potential application and reliability of videotape recording for QCA for clinical studies, recordings of experimental phantom stenoses ${ }^{5-8}$ and clinical coronary artery stenoses before or after balloon angioplasty were as- 
sessed with the new version of a computer-based coronary angiography analysis system. ${ }^{5}$

\section{METHODS}

Experimental image acquisition of phantom stenoses. For the in vitro validation we used radiolucent plexiglass cylinders ( $50 \mathrm{~mm}$ length, $20 \mathrm{~mm}$ in outer diameter) with precision-drilled concentric circular lumens (tolerance 0.01 $\mathrm{mm}$ ) of $0.5,0.75,1.0,1.5,2.0,2.5$, and $3.0 \mathrm{~mm}$ in diameter. The length of each phantom stenosis channel was $20 \mathrm{~mm}$, and the adjacent "normal" channel length of the proximal and distal segments was $30 \mathrm{~mm}$. The plexiglass channel (including the artificial stenosis) was filled with contrast medium (iopamidol 370; $370 \mathrm{mg}$ iodine/ml [Bracco, Milano, Italy]). Digital and cinefilm acquisition was performed with additional plexiglass blocks ( $12.5 \mathrm{~cm}$ anteriorly and 5 $\mathrm{cm}$ posteriorly). These plexiglass blocks provide a more appropriate (kilovolt level and a scatter medium that more closely approximates the radiologic scatter of the human thorax during angiography. Angiograms were performed with the 5-inch field of an image intensifier, with separate recordings and two different focal spots $(0.5 \mathrm{~mm}$, which was used for most of the experimental and clinical series, and $0.8 \mathrm{~mm}$ ) and at an image acquisition rate of 25 frames/sec. The radiographic system settings were kept constant (kilovolt, milliampere, $x$-ray pulse width) in each projection. All phantoms were imaged at the radiographic isocenter of the x-ray gantry ${ }^{9}$ and acquired simultaneously on $35 \mathrm{~mm}$ cinefilm (Kodak CFE type 2711, Paris, France) and digitally (Philips Digital Cardiac Imaging [DCI] system Philips, Best, The Netherlands).

Coronary arteriographic procedure before and after percutaneous transluminal coronary angioplasty (PTCA). Coronary angiography was performed in multiple projections with $8 \mathrm{~F}$ polyurethane catheters (Cordis, Miami, Fla.), in 20 patients before and after PTCA at the Thoraxcenter, Rotterdam. To control vasomotion, intracoronary isosorbide dinitrate ( 1 to $3 \mathrm{mg})^{10}$ was administered before manual injection of contrast medium (iopamidol $370 ; 370 \mathrm{mg}$ iodine $/ \mathrm{ml}$ ) at $37^{\circ} \mathrm{C}$. The 5 -inch field of the image intensifier was selected and the radiographic settings were kept constant (kilovolt, milliampere, $\mathrm{x}$-ray pulse width) in each projection. All clinical images were simultaneously acquired digitally by DCI and on $35-\mathrm{mm}$ cinefilm with frame rates of 25 images $/ \mathrm{sec}$.

Image processing and spatial filtering(edge-enhancement) in the DCl. Both experimental and clinical angiographic images were stored on a $474 \mathrm{MB}$ Winchester disk. The DCI system uses a matrix size of $512 \times 512$ pixels (average horizontal pixel size $200 \mu \mathrm{m}$; density resolution 8 bits $=256$ gray levels). The images were processed with the automated coronary analysis software package of the DCI system. $8,11,12$ Edge-enhanced images were produced by spatial filtering on the DCI system. The algorithm of spatial filtering operates by substituting new pixel values for the original pixel values on the coronary angiogram. ${ }^{13} \mathrm{~A}$ visible horizontal edge of the coronary artery is formed when a string of horizontally connecting pixels displays values that are different from those immediately above or below. Similarly, a vertical edge of the coronary artery is formed when a string of vertically connecting pixels have values different from those immediately to the right or to the left. Oblique edges are generated through combinations of horizontal and vertical components. The default edgeenhancement mode of the DCI system was used. Spatial filtering amplifies the pixel differences between the opacified vessel and its background, thereby providing a more distinct border to the coronary artery. Images with and without edge-enhancement were then directly relayed to the video recorder (Panasonic 7330, Osaka, Japan) and recorded on super-VHS tape (Fuji-film double coating SE60 , Sizuoka, Japan).

Stenosis characteristics. Twenty-one experimental frames and the 51 pre-PTCA and post-PTCA clinical frames were selected for quantitative analysis, and their minimal luminal diameter was measured. Of the clinical angiograms, the 31 pre-PTCA frames consisted of 16 left anterior descending, 10 left circumflex, and 5 right coronary artery lesions. Of the 20 post-PTCA frames evaluated, 10 showed left anterior descending, 8 left circumflex, and 2 right coronary artery lesions. All pre-PTCA lesions had $>50 \%$ diameter stenosis.

Correction of pincushion distortion. Before the performance of the calibration and analyses of the stenoses, computerized correction for pincushion distortion was applied by the recording and subsequent off-line digitization of a centimeter grid placed in front of the image intensifier.

Calibration of images. For the experimental in vitro series, the measurements of the phantom stenoses were calibrated with a contrast-filled $3.0 \mathrm{~mm}$-diameter circular channel in a plexiglass cylinder as a scaling device. This calibration frame was digitized and traced by the automated contour detection algorithm before the series of analyses of the in vitro phantoms was begun. In the clinical study, cinefilm and videotapes were calibrated by the use of the recorded contrast-free catheter tip as a scaling device. The nontapering catheter tip was measured with a precision micrometer (Mitutoyo no. 293-501, Tokyo, Japan; accuracy $0.001 \mathrm{~mm}$ ).

Quantitative analysis in CAAS II. Cinefilms and corresponding frames of videotapes with and without spatial filtering (edge enhancement) were quantitatively analyzed off-line by using the computer-based Cardiovascular Angiographic Analysis System (CAAS II; Pie Medical, Maastricht, The Netherlands). ${ }^{5,14-19}$ In the experimental study a sufficiently long segment of the plexiglass cylinders including the stenosis phantom was selected for analysis. In the clinical study frames without foreshortening or overlapping side branches were selected. Arterial dimensions of clinical frames were measured at specific distances from identifiable branch points in end-diastolic frames. The entire cineframe of size $18 \times 24 \mathrm{~mm}$ is digitized at a resolution of $1329 \times 1772$ pixels in the CAAS II system. During image acquisition of videotape a time-base corrector was implemented to ensure high-quality stand-still images. ${ }^{1}$ The video signal from tapes with and without spatial filtering (edge-enhancement) were digitized at a resolution of $512 \times 512$ pixels by the CAAS II system. In the CAAS II 
Table I. Comparison of phantom diameter and minimal luminal diameter obtained from cinefilm, normal-image videotape, and edge-enhanced videotape in experimental in vitro phantom study

\begin{tabular}{|c|c|c|c|c|c|c|}
\hline Recording medium & Accuracy & Precision & Difference & Correlation & $\begin{array}{c}\text { Linear regression } \\
\text { analysis }\end{array}$ & $S E M$ \\
\hline Cinefilm & -0.10 & \pm 0.08 & $p<0.01$ & 0.997 & $y=0.01+0.93 x$ & 0.05 \\
\hline Normal-image videotape & -0.11 & \pm 0.18 & $p<0.05$ & 0.987 & $y=0.13+0.85 x$ & 0.12 \\
\hline Edge-enhanced videotape & -0.10 & \pm 0.11 & $p<0.01$ & 0.992 & $y=-0.06+0.98 x$ & 0.11 \\
\hline
\end{tabular}

system, the edge-detection algorithm is based on the first and second derivative functions applied to the digitized brightness profile along scan lines perpendicular to a model that uses minimal cost criteria. ${ }^{20,21}$ The contour definition is carried out in two iterations. First, the user defines a number of center-line points within the arterial segment that are interconnected by a straight line and serve as the first model. Subsequently, the program recomputes the center line, determined automatically as the midline of the contour positions that were detected in the first iterations. A computer-derived estimation of the original dimensions of the artery at the site of the obstruction was used to determine interpolated reference values for arterial diameter and area. Manual correction of the automatically detected contours was neither necessary nor performed in either the experimental phantom nor the clinical studies (in routine practice at angiographic core laboratories, subjective manual correction of the detected contours at the minimal luminal diameter is only occasionally performed in the case of complex dissections with parallel luminal extravasation, which was not present in our clinical angiograms).

Statistics. In the experimental study, the individual measurements of minimal luminal diameter were compared with the true phantom diameter by using the paired Student $t$ test and linear regression analysis. The mean of the signed differences between the true phantom diameters and the individual minimal luminal diameter values derived from measurements of cinefilm and of videotape were considered an index of accuracy and the SD of the differences an index of precision. In the clinical study, the mean $\pm \mathrm{SD}$ of the signed differences between measurements of minimal luminal diameter derived from cinefilm and measurements of minimal luminal diameter derived from videotape were used as an index of agreement between measurements from the different recording media. This statistical approach to the comparison of two measurement systems has been previously recommended by Bland and Altman. ${ }^{22}$

\section{RESULTS}

In vitro results. The results of $\mathrm{QCA}$ measurements obtained from cinefilm, videotape with normal image, and videotape with spatial filtering (edge enhancement) and their comparisons with the true phantom diameters are summarized in Table I and displayed graphically in Fig. 1. Of the three record- ing modes, cinefilm was found to provide the most precise measurement results.

Clinical results. The results of measurements from normal-image videotape are plotted against those from cinefilm in Fig. $2, A .{ }^{22}$ The agreement between the two sets of measurements was poor $(0.14 \pm 0.20 \mathrm{~mm}(p<0.01))$. The results of measurements from edge-enhanced video are plotted against those from cinefilm in Fig. 2, $B .{ }^{22}$ Although the agreement between the two sets of measurements was better with edge-enhanced video than with normal-image videotape, the difference between the edge-enhanced videotape and cinefilm measurements still achieved statistical significance $(0.04 \pm$ $0.13 \mathrm{~mm}(p<0.05))$.

\section{DISCUSSION}

We have demonstrated that of the three image recording modes studied, cinefilm produces the most precise QCA measurements. The reasons for this finding may relate to the high resolution afforded by cinefilm frame analysis (1329 $\times 1772$ pixels) compared to the limited resolution provided by the analysis of a single video field (312 lines per field; each video frame consists of two interlaced fields). The noise introduced by the video recording process and by the videotape itself may contribute to the lower precision of the QCA measurements. This video-induced noise was not overcome by our compensatory steps of recording on super-VHS videotape to reduce the signal/noise ratio $^{3}$ and deploying a time-base corrector during image acquisition to overcome jitter. ${ }^{1}$ As was expected, the introduction of a systematic noise such as that associated with video recording did not exert a significant effect on the accuracy of our QCA measurements.

Our studies of both experimental and clinical images indicate that video recording with on-line spatial filtering results in more reliable QCA measurements than videotape without enhancement. These findings support the view that on-line spatial filtering (edge enhancement) before the introduction of video noise provides a more distinct border to the coronary vessel (or phantom stenosis), which is more 

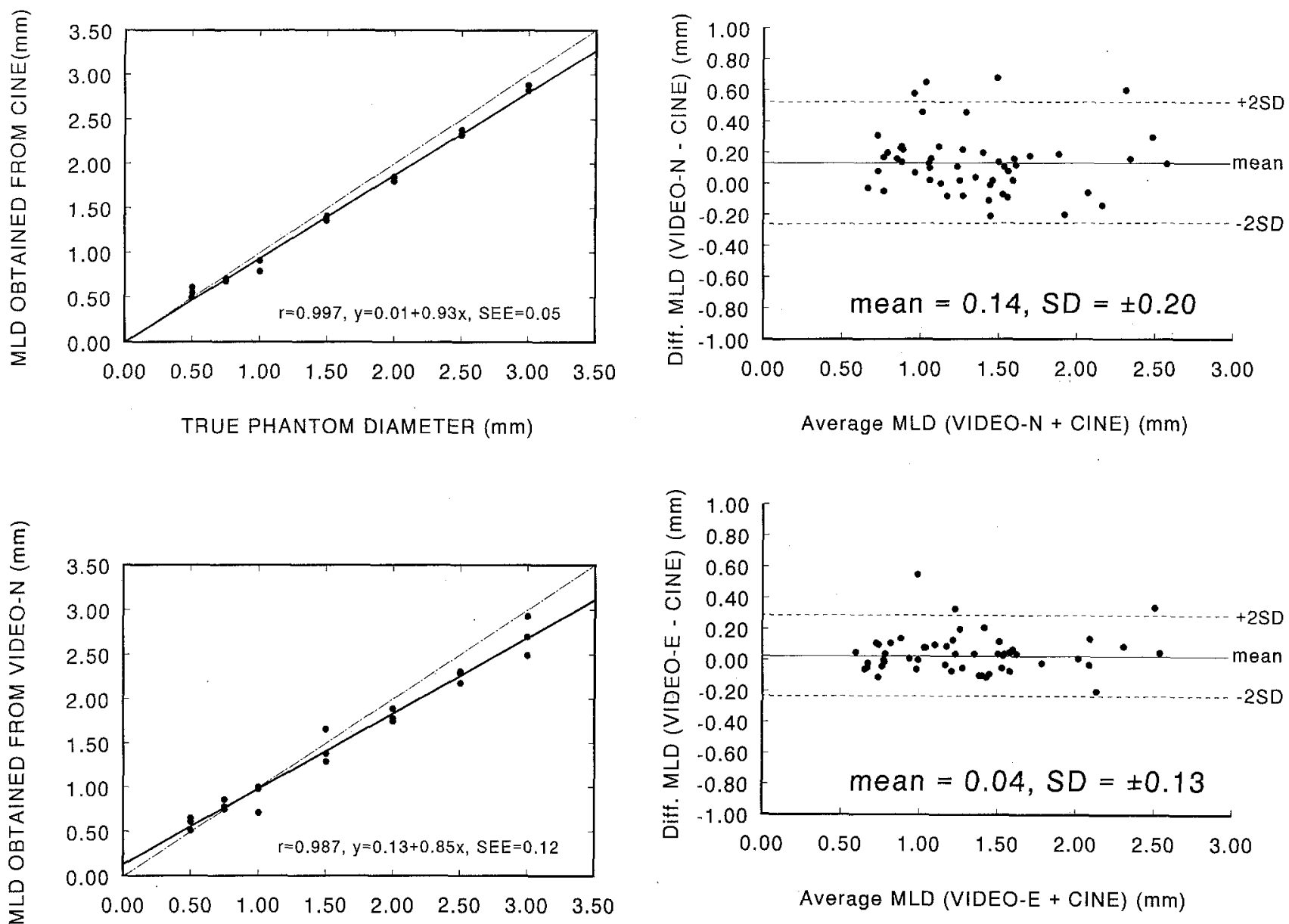

TRUE PHANTOM DIAMETER (mm)

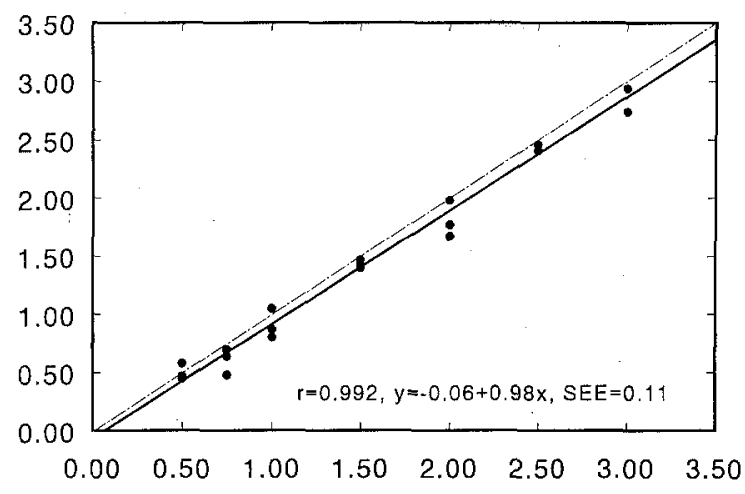

TRUE PHANTOM DIAMETER $(\mathrm{mm})$

Fig. 1. Linear regression analysis of QCA measurements obtained from cinefilm (CINE), normal-image videotape $(V I D E O-N)$ and edge-enhanced videotape (VIDEO-E), against true phantom diameter. Top, Cinefilm vs phantom; Middle, normal-image videotape phantom; Bottom, edgeenhanced videotape vs phantom. $M L D$, Minimal luminal diameter.

Fig. 2. Agreement between measurements obtained from cinefilm and video recordings according to statistical approach proposed by Bland and Altman. ${ }^{22}$ Top, Difference between normal-image videotape and cinefilm measurements has been plotted against their mean. Bottom, Difference between edge-enhanced videotape and cinefilm measurements has been plotted against their mean. Abbreviations as in Fig. 1.

faithfully tracked by the off-line QCA edge-detection algorithm than the vessel border of an unenhanced image.

Study implications. Financial considerations have now become an important factor in the administrative and technical decision-making process of most cardiac catheterization laboratories. A single videotape can store the complete angiographic records of approximately 40 patients at a cost of less than $\$ 1$ per patient; cinefilm increases the cost per patient to $\$ 40$. Our findings suggest that the adoption of videotape with edge-enhanced images may present an acceptable alternative to cinefilm for routine purposes and possibly for QCA purposes under certain circumstances. It should be recognized, however, that the 
addition of any noise or imprecision to the system of off-line QCA will increase the SD of the angiographic results of the study. In turn, this might increase the number of patients needed for detection of a statistically significant difference among two study populations under comparison. ${ }^{23}$ Thus the inclusion of videotape in the design of a restenosis prevention or progression-regression trial may present a false economy by virtue of a concomitant increase in the number of patients required and subsequent greater total study costs.

Study limitation. The edge enhancement of images and subsequent QCA analysis in our study was performed by the Philips DCI system and CAAS II system. Further studies will be required to confirm whether our findings can be generalized to other hardware or software systems. It is conceivable that if an on-line edge-enhancement algorithm was inaccurate, a systematic underestimation or overestimation of vessel diameters could be translated to subsequent off-line QCA measurements.

Conclusion. Despite the application of on-line edge enhancement, the selection of super-VHS videotape and the deployment of a time-base corrector in the processing of video images for off-line QCA, cinefilm continues to present a more reliable image recording medium of coronary angiograms for scientific studies. For routine practice, however, videotape with edgeenhanced images may provide an acceptable alternative.

\section{REFERENCES}

1. Holmes Jr DR, Smith HC, Gray JE, Wondron MA. Clinical evaluation and application of cardiac laboratory high-definition video systems. Cathet Cardiovasc Diagn 1984;10:63-71.

2. Gray JE, Wondrow MA, Smith HC, Holmes DR Jr. Technical considerations for cardiac laboratory high-definition video systems. Cathet Cardiovasc Diagn 1984;10:73-86.

3. Laboratory Performance Standards Committee. Interim standard: videotape recorders for transferring cardiac cinefluorographic studies. Cathet Cardiovasc Diagn 1990;21:58-60.

4. Serruys PW, Umans VAWN, Strauss BH, Suylen BJ, Brand M, Suryapranata $\mathrm{H}$, Feyter PJ, Roelandt JRT. Quantitative angiography after directional coronary atherectomy. Br Heart J 1991;66:122-9.

5. Haase J, Escaned J, Swijndregt EM, Ozaki Y, Gronenschild Ed, Slager CJ, Serruys PW. Experimental validation of geometric and densitometric coronary measurements on the new generation cardiovascular angiography analysis system (CAAS II). Cathet Cardiovasc Diagn 1993;30:104-14.

6. Haase J, van der Linden MMJM, Di Mario Carlo, van der Griessen WJ, Serruys PW. Can the same edge detection algorithm be applied to online and off-line analysis system? Validation of a new cinefilm-based geometric coronary measurement software. AM HEART J 1993;126:31221.
7. Haase J, Nugteren SK, van Swijndregt EM, Slager CJ, Di Mario C, de Feyter PJ, Serruys PW. Digital geometric measurements in comparison to cinefilm analysis of coronary artery dimensions. Cathet Cardiovasc Diagn 1993;28:283-90.

8. Haase J, Di Mario C, Slager CJ, van der Giessen WJ, den Boer A, de Feyter PJ, Reiber JHC, Verdouw PD, Serruys PW. In vivo validation of on-line and off-line geometric coronary measurements using insertion of stenosis phantoms in porcine coronary arteries. Cathet Cardiovasc Diagn 1992;27:16-27.

9. Wollschlager $H$, Lee $P$, Zeiher A, Solzbach U, Bonzel T, Just $H$. Improvement of quantitative angiography by exact calculation of radiological magnification factors. Comp Cardiol 1985;483-6.

10. Ozaki Y, Keane D, Haase J, Baptista J, Meneveau N, de Feyter P, Takatsu F, Serruys PW. Temporal variability and correlation with geometric parameters in vasospastic angina: a quantitative angiographic study. Eur Heart J 1994;15:61-7.

11. van der Zwet PMJ, von Land CD, Loois G, Gerbrands JJ, Reiber JHC. An on-line system for the quantitative analysis of coronary arterial segments. Comp Cardiol 1990;157-60.

12. Reiber JHC, van der Zwet PMJ, von Land CD, Koning G, Loois G, Zorn I, van den Brand M, Gerbrands JJ. On-line quantification of coronary angiograms with the DCI system. Med Mundi 1989;34:89-98.

13. Spatial Data Systems. Eyecom handbook. California: Spatial Data Systems, Inc., 1987:1-67.

14. Serruys PW, Luyten HE, Beatt KJ, Geuskens R, de Feyter PJ, van den Brand M, Reiber JHC, Ten Katen HJ, van Es GA, Hugenholtz PG. Incidence of restenosis after successful coronary angioplasty: a timerelated phenomenon. A quantitative angiographic study in 342 consecutive patients at 1, 2,3, and 4 months. Circulation 1988;77:361-71.

15. Serruys PW, Strauss BH, Beatt KJ, Bertrand ME, Puel J, Rickards AF, Meier B, Goy JJ, Vogt P, Kappenberger L, Sigwart U. Angiographic follow-up after placement of a self-expanding coronary artery stent. $\mathrm{N}$ Engl $J$ Med 1991;324:13-7.

16. Reiber JHC, Serruys PW, Kooijman CJ, Wijns W, Slager CJ, Gerbrand JJ, Schuurbiers JCH, den Boer A, Hugenholtz PG. Assessment of short-, medium-, and long-term variations in arterial dimensions from computer-assisted quantitation of coronary cineangiograms. Circulation 1985;71:280-8.

17. Strauss BH, Serruys PW, de Scheerder IK, Tijssen JGP, Bertrand ME, Puel J, Meier B, Kaufmann U, Stauffer JC, Rickards AF, Sigwart U. Relative risk analysis of the angiographic predictors of restonosis in the coronary wall stent. Circulation 1991;84:1636-43.

18. Serruys PW, Rutsch W, Heyndrickx GR, Danchin N, Mast EG, Wijns W, Rensing BJ, Vos J, Stibbe J. Prevention of restenosis after percutaneous transluminal coronary angioplasty with thromboxane $\mathrm{A}_{2-}$ receptor blockade: a randomized, double-blind, placebo-controlled trial. Circulation 1991;84:1568-80.

19. Umans VA, Hermans W, Foley DP, Strikwerda S, van den Brand M, de Jaegere $P$, de Feyter P, Serruys PW. Restenosis after directional coronary atherectomy and balloon angioplasty: comparative analysis based on match lesions. J Am Coll Cardiol 1993;21:1382-90.

20. Reiber JHC, Kooijman CJ, Slager CJ, Gerbrands JJ, Schuurbiers JHC, Boer A den, Wijns W, Serruys PW, Hugenholtz PG. Coronary artery dimensions from cineangiogram-methodology and validation of a computer-assisted analysis procedure. Comp Cardiol 1984;131-41.

21. Gronenschild $\mathrm{E}$, Janssen J. A compact system for quantitative cardiovascular angiography analysis. In: Lun KC, Dagoulet $P$, Pienne TE, Rienhoff O (eds.) Medinto 1992. New York: Elsevier Science, 1992:795800

22. Bland JM, Altman DG. Statistical methods for assessing agreement between two methods of clinical measurement. Lancet 1986;2:307-10.

23. Serruys PW, Foley DP, Kirkeeide RL, King SB III. Restenosis revisited: insight provided by quantitative coronary angiography. AM HEART $J$ 1993;126:1243-67. 